\title{
Leadership Style, Organizational Culture and Performance: Evidence from China's Manufacturing Industry
}

\author{
Shiqi $\mathrm{Li}^{1 *}$ \\ ${ }^{1}$ Faculty of Arts \& Social Sciences, National University of Singapore, 119077, Singapore \\ *Corresponding author.Email: lishiqi@u.nus.edu
}

\begin{abstract}
This proposed study aims to measure leadership style (transformational or transactional) on organizational culture and job satisfaction and how these eventually affect organizational effectiveness and performance. The multi-level analysis will be performed for the collecting and processing. This study will study the influence of leadership style on organizational culture and performance in China's manufacturing industry. Our data are collected from 300 employees in 30 departments in the manufacturing industry. By using Multi-Factor Questionnaire (MLQ) and interview methods, the findings of this study can be concluded. The result aims to give more solid evidence to unveil how the different leadership styles affect organizational performance. As result, the transformational and transactional leadership styles will positively affect organizational culture, then organizational culture will positively affect the effectiveness and performance of the organization.
\end{abstract}

Keywords: Transformational leadership, Transactional leadership, multi-level analysis, manufacturing industry, China.

\section{BACKGROUND}

The manufacturing industry is the main body of the real economy, an important field of supply-side structural reform and technological innovation, and the main content of constructing a modern economic system. The high-quality development of the manufacturing industry is an important part of the high-quality development of the economy. It is related to key strategies such as building a well-off society in an allaround way and building a modern socialist country in an all-around way. It fundamentally determines China's future comprehensive strength and international status. In the manufacturing industry, the quality of company leaders is also considered the key to maintaining and improving competitiveness. The leadership of company managers has long been considered an important factor necessary for the company's success [1].

The importance of leadership for direction, driving, and developing high-performing organizations is acknowledged by researchers and practitioners [1]. The study of leadership began with basic principles of reinforcement [2]. Early research recognized that leaders and followers enter into relationships to establish what is being exchanged, negotiate the costs and benefits of this exchange, and determine whether it is satisfactory to their self-interests [3]. These interactions eventually affect organizational effectiveness.

Leadership is perhaps one of the most critical management aspects of a company, organization, and nation. It is a significant factor that contributes immensely to organizations' general well-being. A series of theories are being put forward to explain leadership effectiveness, the most prominent leadership theories among them are transformational and transactional leadership theories. Most researchers agree that transactional and transformational leadership are different in concept and practice, and both could result in higher levels of individual, group, and organizational performance. The mechanism of how leadership is related to organizational effectiveness \& performance remains unclear. Bryant found that transformational leadership may be more effective at creating and sharing knowledge at the individual and group levels.

In contrast, transactional leadership is more effective at exploiting knowledge at the organizational level [4]. 
Bass, Howell and Avolio integrated transactional and transformational leadership styles and found them to complement each other in achieving desired goals and outcomes [5,6]. Many authors assume a strong relationship between organizational culture and leadership. In addition, the topics of leadership style, organizational culture and performance have also been studied worldwide, but few empirical studies have shown the connection between these three concepts.

Thus, this proposed research will investigate the relations between leadership styles, organizational culture, job satisfaction, organizational effectiveness, and performance via multi-level analysis. This article uses the manufacturing industry as an example. We use the method of questionnaire adjustment to survey different employees. Unlike most previous studies, the differences from individual and team levels to gross will be analyzed. The result aims to give more solid evidence to unveil how the different leadership styles affect organizational performance.

This review paper takes the Chinese manufacturing industry as a research object because, from the Worldbank, China's manufacturing industry has completed its primitive accumulation and has achieved a relatively high manufacturing level. The development of the manufacturing industry has achieved worldrenowned achievements. The added value of the manufacturing industry has been ranked first in the world since 2012. The manufacturing industry still drives China's real GDP growth the most, driving economic growth by 1.6 percentage points. Its contribution to global manufacturing is as high as $35 \%$, surpassing the United States and Japan. At present, China is the only country globally that has a complete industrial system with all products in 39 major categories, 191 medium categories, and 525 subcategories in the United Nations Industrial Classification, including 220 types of steel, automobiles, and mobile phones. The output of the abovemanufactured products is the largest globally, and the import and export volume has ranked first in the world for many years. During the 2020 new crown pneumonia epidemic, a strong manufacturing base played a vital role in China's rapid defeat and provided strong support for global epidemic prevention and control.

The remainder of this study is organized as follows. After developing our hypotheses in section 3, we introduce our data and methodology in section 4, including sample, data source, research design and empirical model. Finally, we conclude the paper in section 5 .

\section{THEORETICAL FRAME OF REFERENCE}

\subsection{Transformational and Transactional Leadership}

Leadership theory distinguishes between different leadership styles: transformational and transactional $[7$, 8]. Burns has introduced the model of transformational leadership, which identifies the employees are motivated to work for transcendental goals and higherlevel self-actualizing needs, rather than external payoffs [9]. Research finds transactional leadership better predicted individual task performance, while transformational leadership predicted better contextual performance, which indicates the performance above and beyond what is delineated by job requirements alone [10]. Both leadership styles augment each other to achieve higher employee performance levels, but the difference lies in goal setting and motivation methods.

Transactional leadership typically involves the use of contingent rewards to align employee's self-interest with organizational goals. When desired rewards are contingent on specific efforts or results, employee selfinterest is expected to energize, direct, and sustain behavior toward those efforts and results. In contrast, a transformational leader develops a vision of the goals, strives to share this vision, and tries to sustain the shared vision in the long term. Thus, transformational leadership is conceptualized as leader behaviors that seek to develop, share, and maintain a vision. These behaviors are categorized as transformational because they are intended to stimulate employee internalization of the values and goals implied by the concept and make employees transcend their self-interest and strive toward organizational objectives.

Transformational and transactional leadership strategies are often treated as stand-alone leadership behaviors in empirical studies. In order to inform practice and guide future research efforts, it is important to consider and investigate the effects of combined leadership strategies in a robust field-experimental design.

\subsection{Organizational Culture}

The organizational culture that influences firm effectiveness is an assumption implicitly held by many managers and researchers, although few empirical studies have provided detailed insight into the relationship. Comparative studies have proved the specific cultural orientations are conducive to organizational performance and effectiveness [11]. The US healthcare facilities study suggests that employee attitudes mediate the culture-effectiveness relationship [12]. 
The important part of organizational culture building is articulating the leader's vision to the followers and aligning them. Schein indicates that the formation of organizational culture takes place in three ways [13]. Firstly, a filtering process could happen whereby the job-seeker with a similar set of values as the leader is selected. In contrast, those candidates with incompatible values are filtered out. Secondly, as the candidates are chosen, they undergo a socialization process that gradually gets molded in organizational demands. The employee comes in contact with the anecdotes, rituals, symbols, myths, and behavioral norms of that organization, imbibe them gradually and practices the cultural standards. Thirdly, acting as a role model, the leader sets examples that followers tend to follow. If the leader wants to create a robust ethical style, the leader should walk and talk as a visible role model. Through the appraisal system and a reward system that underscores ethical conduct, the leader establishes a reinforcement mechanism whereby ethical behavior becomes a part of that company and is followed by all the staff.

The competing values model of organizational culture measurement consists of two dimensions with contrasting poles shown in figure 1 [14]. The first dimension represents the organization's point of view. The focus can either be directed externally or internally depending on the central issue from the environment or the organization itself. Combining these two dimensions gives four orientations of organizational culture, including support, innovation, rules, and goal.

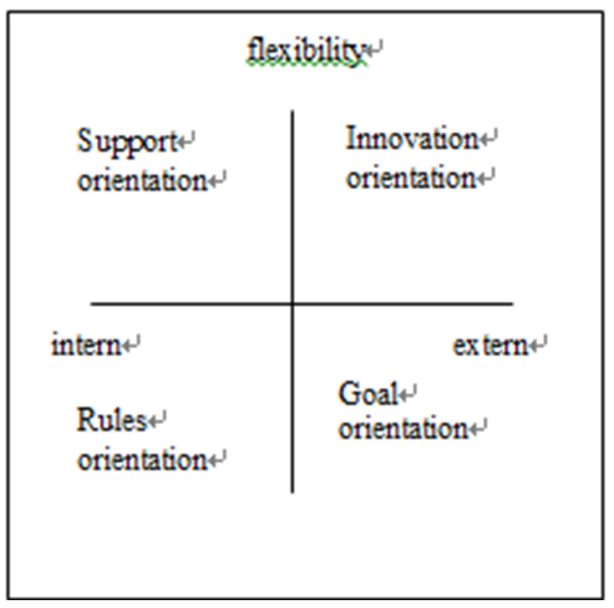

Figure 1 The organizational culture model

\subsection{Job Satisfaction}

Many studies have investigated the effects of transformational leadership at an individual level [15]. In particular, numerous investigations found that individual perceptions of supervisor leadership positively related to job satisfaction [15]. Transformational leaders show individualized consideration and are thereby able to recognize and respond "to each individual's abilities, aspirations, and needs" [16]. They adjust their inspirational motivation and idealized influence behavior to individual followers' specific goals and interests [17] and ensure that each follower can voice concerns through intellectually stimulating behavior [18]. Therefore, the followers' job satisfaction will, in part, rely on these and similar direct, individual experiences with their supervisor.

\subsection{Leadership and Organizational Effectiveness \& Performance}

The value of different leadership is the potential to improve organizational effectiveness and performance. Performance is "the actual achievement of a unit to its intended achievements, such as the attainment of goals and objectives" [19]. Performance in public service organizations or none-profitable organizations is usually complex and multi-faceted [20]. So, in this research, the effectiveness is the achievement of formal objectives and an essential aspect of performance.

Many studies support that transformational leadership will lead to higher performance [15], but they are mainly based on observational cross-sectional data, which may overestimate effects. Transformational leadership has been linked with positive performance effects among public employees when exposed to job design initiatives in a field experiment [21]. Comparing with transformational leadership, transactional leadership behaviors concerning performance are much more limited. However, an experimental study of performance-contingent rewards among nurses shown that pecuniary rewards can increase performance considerably, although the effect is much smaller when financial tips are visible to others [21]. The study suggests the positive effects of contingent rewards on schoolteachers [22], and evidence from Israel confirms that performance-based school pay can affect student outcomes in both the short and long term [23].

\section{HYPOTHESES}

H1: Leadership will positively affect organizational effectiveness and performance.

H2a: Transformational and transactional leadership will positively affect the organizational culture

H2b: Leadership will positively affect the job satisfaction of individuals.

H3: Organizational culture will positively affect organizational effectiveness and performance.

H4: Job satisfaction will positively impact organizational effectiveness and performance. 


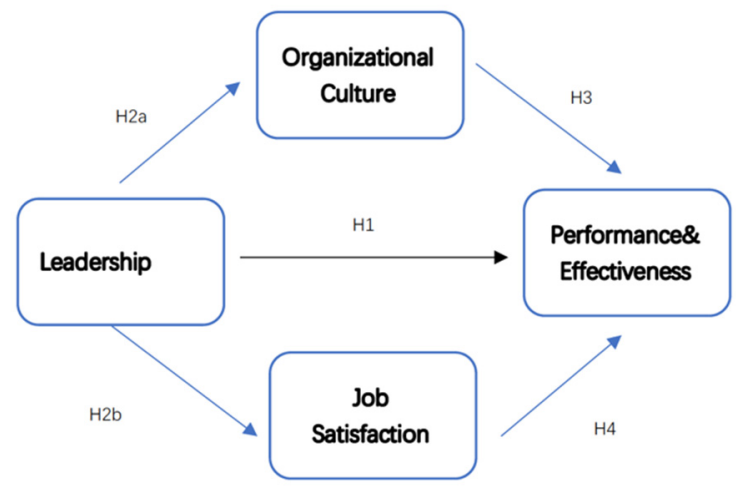

Figure 2 Hypothesized model for investigation ( $\mathrm{H}$ indicate hypothesis, dash lines indicate direct relations)

\section{METHODOLOGY}

\subsection{Sample and Procedure}

The sample in this study will be gathered from approximately 300 employees in 30 departments from the manufacturing industry. The Multi-Factor Questionnaire (MLQ) and interview method will be used for data collection. For the effectiveness\& performance, the data will be collected through the different accessible methods [24].

\subsection{Questionnaires}

Leadership: In this study, an adapted version of the MLQ 8Y will be used for the transformational, transactional leadership assessment [25]. The questionnaire instructs respondents to judge how often their manager displays specific behavior, using a fivepoint scale ('frequently' to 'not at all). Sample items for two scales of interest are Transformational leadership (18 items): I am ready to trust the person I am rating to overcome any obstacle. Transactional leadership (9 items): The person I am rating points out what I will receive if $\mathrm{I}$ do what is required.

Culture: In order to measure the organizational culture in this study. The questionnaire instructs respondents to judge how characteristic the organization is on a six-point scale (from 'very' to 'not at all) 37 items in total. Sample items for the four evaluative orientations are Support, Innovative, Rules, and Goal orientation.

Job satisfaction: The various facets of job satisfaction were measured as follows firstly, using the short version of the Minnesota Satisfaction Questionnaire [26], the scale from 1- very unsatisfied to 5- very satisfied.

\subsection{Expected Outcomes}

By conducting a questionnaire among companies and organizations, the study is expected to make these conclusions: Firstly, the transformational and transactional leadership styles will positively affect the development of organizational culture. Secondly, the organizational culture will positively affect the effectiveness and performance of the organization.

\section{CONCLUSION}

The research results of this article enrich the research on Western leadership styles and organizational culture and the theory of business performance in the Chinese context and help us reexamine the actual situation of China's manufacturing industry adapt to China's specific conditions. This article uses a questionnaire method, based on a questionnaire survey of 300 domestic manufacturing employees, and finds that companies should attach importance to leadership style and organizational culture and the impact on business performance.

The research in this article is still in the exploratory stage, so there are many limitations. First, the questionnaire standard is taken from Western researchers, which inevitably has cross-cultural issues. Second, the identification of organizational culture types is not clear in this research. In fact, cultural types can be divided in more detail, which needs to be further explored. These limitations require more effort in the future.

\section{REFERENCES}

[1] Van Wart, M., 2013. Administrative leadership theory: A reassessment after 10 years. Public Administration, 91(3), pp.521-543.

[2] Barnard, C.I., 1968. The functions of the executive (Vol. 11). Harvard university press.

[3] Hollander, E.P., 1958. Conformity, status, and idiosyncrasy credit. Psychological review, 65(2), p.117.

[4] Bryant, S.E., 2003. The role of transformational and transactional leadership in creating, sharing and exploiting organizational knowledge. Journal of Leadership \& Organizational Studies, 9(4), pp.32-44.

[5] Bass, B.M., 1999. Two decades of research and development in transformational leadership. European journal of work and organizational psychology, 8(1), pp.9-32. 
[6] Howell, J.M. and Avolio, B.J., 1993. Transformational leadership, transactional leadership, locus of control, and support for innovation: Key predictors of consolidatedbusiness-unit performance. Journal of applied psychology, 78(6), p.891.

[7] Bass, B.M. and Bass Bernard, M., 1985. Leadership and performance beyond expectations.

[8] Bass, B.M. and Riggio, R.E., 2006. Transformational leadership.

[9] Burns, J. M. (1978). Leadership. New York: Harper Collins.

[10] Wang, H., Tsui, A.S. and Xin, K.R., 2011. CEO leadership behaviors, organizational performance, and employees' attitudes. The leadership quarterly, 22(1), pp.92-105.

[11] Denison, D.R., Haaland, S. and Goelzer, P., 2004. Corporate culture and organizational effectiveness: is Asia different from the rest of the world?. Organizational dynamics, 33(1), pp.98-109.

[12] Gregory, B.T., Harris, S.G., Armenakis, A.A. and Shook, C.L., 2009. Organizational culture and effectiveness: A study of values, attitudes, and organizational outcomes. Journal of business research, 62(7), pp.673-679.

[13] Schein, E. H. (1988). Organizational culture and leadership. San Francisco: Jossey-Bass Publishers.

[14] Quinn, R.E. (1988) Beyond Rational Management. London: Jossey-Bass.

[15] Judge, T.A. and Piccolo, R.F., 2004. Transformational and transactional leadership: a meta-analytic test of their relative validity. Journal of applied psychology, 89(5), p.755.

[16] Walumbwa, F. O., Orwa, B., Wang, P., \& Lawler, J. J. (2005). Transformational leadership, organizational commitment, and job satisfaction: A comparative study of Kenyan and US financial firms. Human resource development quarterly, $16(2), 235-256$.

[17] Chun, J. U., Yammarino, F. J., Dionne, S. D., Sosik, J. J., \& Moon, H. K. (2009). Leadership across hierarchical levels: Multiple levels of management and multiple levels of analysis. The Leadership Quarterly, 20(5), 689-707.

[18] Liu, W., Zhu, R., \& Yang, Y. (2010). I warn you because I like you: Voice behavior, employee identifications, and transformational leadership. The leadership quarterly, 21(1), 189-202.

[19] Jung, C.S., 2014. Why are goals important in the public sector? Exploring the benefits of goal clarity for reducing turnover intention. Journal of Public Administration Research and Theory, 24(1), pp.209-234.

[20] Andersen, L.B., Heinesen, E. and Pedersen, L.H., 2014. How does public service motivation among teachers affect student performance in schools?. Journal of Public Administration Research and Theory, 24(3), pp.651-671.

[21] Bellé, N., 2014. Leading to make a difference: A field experiment on the performance effects of transformational leadership, perceived social impact, and public service motivation. Journal of Public Administration Research and Theory, 24(1), pp.109-136.

[22] Dee, T.S. and Wyckoff, J., 2015. Incentives, selection, and teacher performance: Evidence from IMPACT. Journal of Policy Analysis and Management, 34(2), pp.267-297.

[23] Lavy, V., 2020. Teachers' Pay for Performance in the Long-Run: The Dynamic Pattern of Treatment Effects on Students' Educational and Labour Market Outcomes in Adulthood. The Review of Economic Studies, 87(5), pp.2322-2355.

[24] Richard, P.J., Devinney, T.M., Yip, G.S. and Johnson, G., 2009. Measuring organizational performance: Towards methodological best practice. Journal of management, 35(3), pp.718804.

[25] Den Hartog, D.N., Van Muijen, J.J. and Koopman, P.L., 1996. Linking transformational leadership and organizational culture. Journal of leadership studies, 3(4), pp.68-83.

[26] Weiss, D. J. (1967). Minnesota satisfaction questionnaire. University of Minnesota, industrial relations Center, work adjustment project. 